\title{
DEVELOPING A POLICY FOR POST DISASTER RECONSTRUCTION PRIORITIZATION: A LESSON LEARNT FROM NEPAL'S EARTHQUAKE 2015
}

\begin{abstract}
In 2015, Central Nepal was shaken by a massive earthquake causing large number of loss of life and damage to private and public property. The disaster received an immediate global attention. Nepalese government received significant support from international agencies in the form of rescue and relief operations as well as commitments of funds for reconstruction. However significant progress has not been achieved in reconstruction of damaged structures even after three years of the devastation. There may be several reasons behind this. One of the reasons is the lack of proper reconstruction framework. The entire damaged infrastructure cannot be reconstructed at the same time because of low economy and lack of enough funds. The Nepalese government failed to prioritize the sectors so that the reconstruction can be completed in a stepwise manner based on the priority. The prioritization process is complex as one has to consider multiple factors, sub- factors and the alternatives to be prioritized. Further, it becomes very important to take care of all the stakeholders' interest in the matter. The process requires multi-criteria decision analysis. This research develops a decision making model based on Analytic Hierarchy Process which can assist government in prioritizing post disaster reconstruction process. The decision making model can be applicable to various kinds of disasters in developing countries.
\end{abstract}

Keywords: AHP, MCDM, disaster, reconstruction.

\section{Introduction}

On April 25, 2015 an earthquake of magnitude 7.8 in Richter scale struck central Nepal. According to the report of WHO (2015), 4.2 million people were affected; 2.8 were displaced; 17,866 were injured and 8046 died. Furthermore, 26 hospitals were damaged and more than 900 primary health care centers and health posts have been rendered nonfunctional. Similarly near about 755,549 residential building, 4000 government offices and 8200 school buildings were damaged. Apart from this thousands of monuments and heritages were damaged.

The country received tremendous support from international agencies during the time of earthquake. Developed countries and other agencies announced large sum of money for the relief and reconstruction works. Some of the countries have already provided their support and some are still in the form of commitments. The total amount deposited was not sufficient for the starting reconstruction of all sectors. Significant amount of money was spent in temporary shelters and most of the earthquake victims do not have any choice other than living in temporary houses even after almost three years of earthquake. 
Since the fund available was not sufficient for the total reconstruction of the damaged structures, lack in planning and failing on prioritization caused the reconstruction work to be very slow and ineffective. The government seems to be perplexed as it is not finding ways to start and accomplish the reconstruction process. Most of the experts of the reconstruction believe that the government should prioritize the sectors so that most important sector gets the highest priority and less important one gets the least priority. Prioritization not only provides the path for the reconstruction but also an important move to accomplish an objective in low economy situation.

All the damaged sectors are important based on their utility and situation. It becomes very difficult to prioritize them. One has to consider several factors, sub-factors and stakeholders during the process. It is a true case of multi criteria decision making (MCDM) and among the various tools available for the MCDM, this research uses Analytic Hierarchy Process (AHP).

\section{Motivation for the research}

Natural disasters like landslide, flood, earthquakes etc. are frequent phenomena in Nepal. Further, there has been a history of colossal disaster like earthquake. The country is not prepared for larger disasters which seem to repeat every few decades. Similar was the situation in April 25, 2015 when earthquake hit central region of Nepal. The disaster caused huge damages to lives and properties. The country received immediate response and support from worldwide and was able to recover in quick time. But the major problem was the reconstruction after the earthquake. Although the commitment from international agencies was encouraging, there was not enough money to start reconstruction of all the damaged structures. Further, the government was not able to fully immerse itself in the process as the country was a in the process of drafting its constitution. Due to this the reconstruction process was not effective and more than half of the damaged structures have not been reconstructed till date. With the limited fund, the government was in dilemma regarding which sector should get the first priority. Is it the individual homes or the government offices or the hospitals? All these sectors are very important. One cannot easily decide which should get first priority and which should get the last. One has to consider multiple criteria and sub criteria. Further, the process becomes more complex because multiple actors (stakeholders) need to be considered.

This research can be useful not only to address the current situation of Nepal but is applicable to all the post disaster reconstruction process not only in Nepal but also in other developing countries with low economy.

Research question

Which sector should get the highest priority in post disaster reconstruction process?

\section{Literature Review}

Research works have highlighted the need of reconstruction on building disaster-resilient cities and communities with long term vision to be better prepared against possible future disasters. A Global Forum on Science and Technology for Disaster Resilience (WG4, 2017) highlighted that the reconstruction need to be structured systematically focusing on 
issues like rebuilding economy, rebuilding livelihood and rebuilding regional communities with consensus among all the stakeholders.

Jha A.K.et al (2010) stated that a good reconstruction policy helps reactive communities and empowers people to rebuild their housing, their lives, and their livelihood. Further, the reconstruction policy and plan should be realistic but ambitious with respect to disaster risk reduction. Some of the actors identified during the process were: national government, provincial government, local government, community, project facilitators and technical experts.

Nepalese government reconstruction and resettlement act 2015 provides some of the factors that need to be considered during the process as local needs, individual and community preference, social and cultural dynamics and economical. Further, it also highlights the planned reconstruction sectors as: road and bridges; airports; electricity and energy; drinking water; irrigation; health sectors, educational sectors; community houses and historical sites and monuments (Post Disaster Recovery Framework, 2015).

There has not been any work done regarding prioritization of post disaster reconstruction sectors. Further, responsibility of the government and psychological aspect of the victims and other stakeholders has not been found to be considered in the research. This, research uses Analytic Hierarchy Process (AHP) for prioritization of reconstruction sectors. AHP is capable of breaking complex problems into smaller parts that can be easily handled by human intelligence (Saaty, 2008)

\section{Objectives}

The major objective of this research is to develop a decision making model for prioritization of sectors for reconstruction after disaster in developing countries.

\section{Research Design}

This research adopted four tools in addition to literatures: questionnaire, Delphi method, one on one interview and model development using AHP. A pair wise comparison questionnaire based on AHP model has been used for data collection. 32 valid samples have been collected 8 from each of the identified groups.

One on one interview was conducted with each of the respondents with the proper demonstration of pair wise comparison process and the inconsistency that may result. Individual data has been checked for consistency. Geometric mean of the valid data collected from individual respondents has been used for further calculation and prioritization of alternatives.

\section{Model Development}

AHP model consists of five levels. Level one is the goal of the research, prioritization of post disaster reconstruction sectors. Level two consists of major stakeholders (actors) during the process. Level three and level four consists of major factors and sub-factors respectively that need to be considered during the prioritization process. Finally, level five consists of all the post disaster reconstruction sectors (alternatives). The hierarchical model developed during the process is shown below. 


\section{Prioritization of Post Disaster Reconstruction}

Level

1

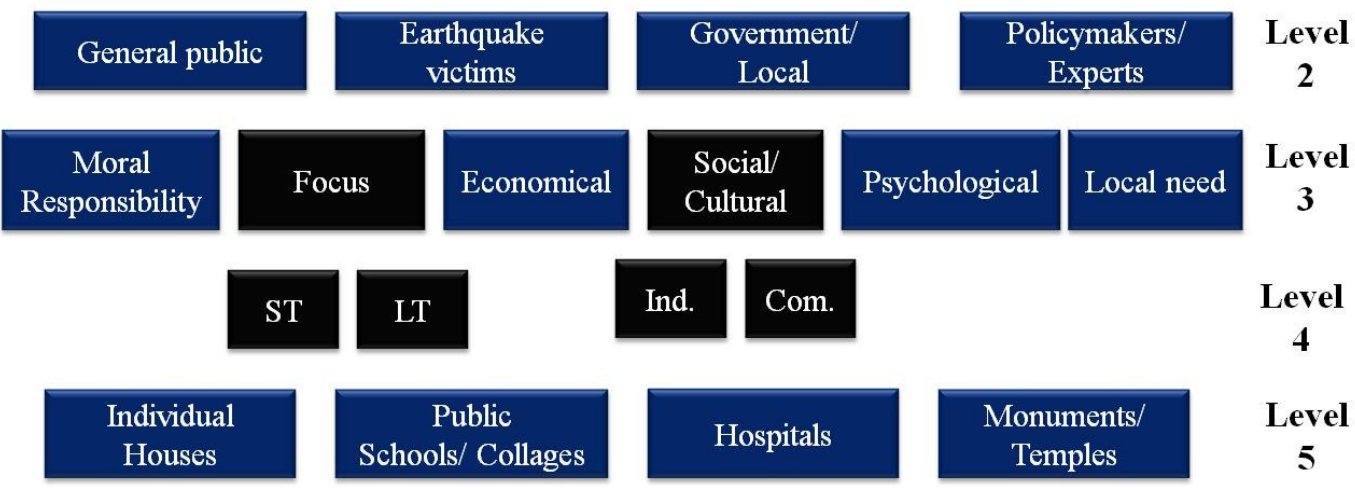

\section{ST: Short Term, LT: Long Term, Ind.: Individual, Com: Community}

Fig: AHP Model for prioritization of post disaster reconstruction

\section{Limitations}

There is no unanimity about the best method of aggregating the responses. The method relies on subjective judgments for the analysis. The weights that are assigned to the decision makers can be tilted in favor such that the result will reflect the opinion of a selected few people. Maintaining consistency is also a very critical factor for the members' views to be accurately reflected in the results. Within a small group, an inconsistent input from a single member can immediately have an effect on the overall rankings.

\section{Conclusions}

This study is probably the first ever study done in the field of post-disaster reconstruction and rehabilitation prioritization. Further, the analysis of the research is based on MCDM, which is very new in the area of disaster management and reconstruction. This research could be a good model for post disaster reconstruction prioritization for the countries with low economy within the constraints of resources and time. Further, it could provide guideline for government and private sectors for identifying stakeholders and alternatives for reconstruction from the stakeholders' perspective. Although the research model has been developed from the background of earthquake, the model is valid in the reconstruction after all types of disaster.

\section{Key References}

Jha A.K.et al. (2010), Safer Homes, Stronger Communities: A Handbook for Reconstructing after Natural Disasters, The International Bank for Reconstruction and Development/ The World Bank. 
Developing a policy for post disaster reconstruction prioritization: A lesson learnt from Nepal's earthquake 2015

Post Disaster Recovery Framework. (2015), Government of Nepal, National Reconstruction Authority, Kathmandu April 2016.

Saaty, T. L. (2008), Decision making with the analytic hierarchy process, Int. J. Services Sciences, 1(1), 83-98.

WG4. (2017), Priority 4: "Build Back Better" in recovery, rehabilitation and reconstruction, A Global Forum on Science and Technology for Disaster Resilience, Tokyo, Japan, November 23- 25, 2017

WHO-Sitrep14. (2015), Situation report 14, World Health Organization, Country Office for Nepal. 